\title{
Synoptic environments and characteristics of cold air outbreaks in the Irminger Sea
}

\section{Journal Article}

\section{Author(s):}

Papritz, Lukas (D)

Publication date:

2017-08

Permanent link:

https://doi.org/10.3929/ethz-b-000379989

Rights / license:

In Copyright - Non-Commercial Use Permitted

Originally published in:

International Journal of Climatology 37(51), https://doi.org/10.1002/joc.4991 


\section{Synoptic environments and characteristics of cold air outbreaks in the Irminger Sea}

Lukas Papritz ${ }^{1 *}$

${ }^{1}$ Geophysical Institute, University of Bergen and Bjerknes Centre for Climate Research, Bergen, Norway

${ }^{*}$ Corresponding author address:

Lukas Papritz, Geophysical Institute, University of Bergen and Bjerknes Centre for Climate Research, Allegaten 70, Postboks 7803, 5020 Bergen, Norway

E-Mail: lukas.papritz@uib.no 
Cold air outbreaks (CAOs) are the dominant cause of intense wintertime upward heat fluxes in the Irminger Sea. In this study, the climatological pathways of Irminger Sea CAO airmasses and the evolution of airmass properties, as well as the large-scale synoptic environments leading to $\mathrm{CAO}$ formation are examined for winter. To that end, a comprehensive, multi-decadal climatology of Irminger Sea CAO airmasses using kinematic trajectories is presented, complemented by a composite analysis of the large-scale synoptic environment for intense CAO events.

The following three synoptic environments conducive for $\mathrm{CAO}$ formation are identified: (i) The westerly environment is characterised by an upper-level trough crossing Greenland and inducing strong westerly winds at crest level, accompanied by either cyclogenesis or the intensification of an existing cyclone in the lee of Greenland. The associated CAO airmasses originate in the Canadian Arctic, overflow southern Greenland, and descend into the Irminger Sea with an according imprint in their thermodynamic evolution. (ii) In the easterly cyclonic environment, one or multiple cyclones in the Nordic Seas induce northerly winds along Greenland's eastern coast that transport Arctic airmasses from Fram Strait to Denmark Strait. (iii) The easterly anti-cyclonic environment, finally, is dominated by an anti-cyclone over Greenland with similar airmass origins and pathways as in the easterly cyclonic environment. The two easterly environments represent the limiting cases of an intermediate spectrum, whereas in contrast the westerly environment is clearly distinct. Katabatic drainage from northern Greenland contributes to the $\mathrm{CAO}$ airmasses in both easterly environments, whereas in
\end{abstract}


25 the easterly cyclonic environment also marine airmasses from the Nordic Seas are

26 involved. An important conclusion of this study is that the amount of heat ex-

${ }_{27}$ tracted from the ocean by a CAO airmass depends critically on its pathway, and 28 thus on the synoptic environment. 


\section{Introduction}

The Irminger Sea encompasses the waters that extend from Cape Farewell - the southernmost tip of Greenland - to Iceland (see Fig. 1 for location names). During winter it is a region of highly variable, in many aspects extreme, climatic conditions: It comprises the stormiest portions of the world's oceans with globally the highest frequency of near-surface wind speeds in excess of $20 \mathrm{~m} \mathrm{~s}^{-1}$ (Sampe and Xie, 2007). In addition to that, it is a breeding ground for extratropical cyclones, many of them propagating north-eastwards into the Nordic and Barents seas - a peculiarity reflected in a high rate of lee cyclogenesis (Wernli and Schwierz, 2006; Dacre and Gray, 2009). Furthermore, recent evidence has revived the long existent notion that heat losses to the atmosphere in the Irminger Sea contribute to the formation of North Atlantic Deep Water (Nansen, 1912; Pickart et al., 2003a,b; Våge et al., 2009b, 2011), which constitutes the deep limb of the Atlantic meridional overturning circulation. The exchanges of heat across the atmosphere ocean interface in the Irminger Sea, therefore, have climatic influences far beyond the region itself (cf. Buckley and Marshall, 2016). As a consequence, a detailed understanding of the processes shaping air-sea heat fluxes is highly relevant for understanding the complex climate of the North Atlantic as a whole.

In this study, I focus on a particular type of wintertime weather event that plays a key role in controlling air-sea heat exchanges: marine cold air outbreaks (CAOs). In fact, CAOs account for more than $80 \%$ of the wintertime oceanic heat loss over most parts of the Irminger Sea (Papritz and Spengler, 2016). Previously, Irminger Sea CAOs have been investigated in the context of climatological studies addressing CAOs over the entire north-east Atlantic (Kolstad et al., 2009; 
Papritz and Spengler, 2016); still fundamental questions regarding the synoptic conditions leading to their formation, as well as their characteristics remain, as I aim to outline in the following.

Based on a composite analysis, Kolstad et al. (2009) found that Irminger Sea CAOs typically occur in the presence of a deep Icelandic Low with its center over the Irminger Sea, and an upper-level trough slightly displaced to the west. This configuration of the large-scale flow leads to the transport of cold airmasses from the Canadian Arctic into the Labrador Sea basin. Consequently, CAOs in the Irminger Sea are often concomitant with CAOs in the Labrador Sea (Kolstad et al., 2009). The configuration of the flow suggests further that Irminger Sea CAO airmasses originate from the Labrador Sea sector. Kolstad et al. (2009) also noted a particular case (their case 8), however, where northerly winds over Denmark Strait brought cold airmasses into the Irminger Sea region.

Indeed, calculations of kinematic trajectories revealed that climatologically two pathways of airmasses leading to CAO formation in the Irminger Sea exist, a western and an eastern pathway (Papritz and Spengler, 2016). Accordingly, in this study I will refer to CAOs formed by airmasses following the western or eastern pathways as westerly or easterly CAOs, respectively. The airmasses of westerly CAOs originate over the Canadian Arctic and the Labrador Sea, overflow the plateau of southern Greenland, and descend as downslope flows. In contrast, most of the airmasses of easterly CAOs have their origin in the Arctic basin following Greenland's eastern coast from Fram Strait southward with contributions of katabatic drainage from Greenland's plateau, as well as from the Nordic Seas. The existence of these two pathways indicates that a richer spectrum of synoptic conditions can induce CAOs in the Irminger Sea than the composite analysis by 
Kolstad et al. (2009) suggests. Hence, it is one of my main goals to elucidate the large-scale environments leading to $\mathrm{CAO}$ formation in the Irminger Sea.

The large-scale flow over and east of Greenland is dominated by Greenland blocking (e.g., Hanna et al., 2016), which is characterized by a quasistationary anticyclone over Greenland, the north-eastern branch of the North Atlantic storm track, and cyclogenesis in the lee of Greenland (Dacre and Gray, 2009). The anticyclonic flow associated with Greenland blocking provides steady northerly winds along Greenland's eastern coast, favorable for the long-range transport of Arctic airmasses contributing to easterly CAOs. However, a sequence of consecutive cyclones might also provide such transport, e.g., when one storm that propagated into the Nordic Seas is followed by another storm in the Irminger Sea. Thus, the relative importance of Greenland anti-cyclones and cyclones in the Nordic Seas for the formation of easterly CAOs remains an open question.

At sub-synoptic scale, the intense interaction of the large-scale flow with Greenland's steep coastal orography and the $3000 \mathrm{~m}$ high ice sheet leads to a variety of high wind speed phenomena. Among them are barrier winds associated with promontories along Greenland's coast in the northern portions of the Irminger Sea and Denmark Strait (e.g., Petersen et al., 2009; Harden et al., 2011; Harden and Renfrew, 2012), as well as westerly tip jets south-east of Cape Farewell (Doyle and Shapiro, 1999; Moore and Renfrew, 2005; Moore et al., 2008; Våge et al., 2009a). Furthermore, katabatically enforced downslope winds bring cold airmasses from the ice sheet down into the Irminger Sea, for example, in the Ammassalik valley (Heinemann and Klein, 2002; Oltmanns et al., 2014). The ocean can loose tremendous amounts of heat during such high wind speed events. For example, Oltmanns et al. (2014) estimated that up to $20 \%$ of the winter- 
time heat loss in the Irminger Sea occurs in association with intermittent downslope wind storms. Furthermore, Harden et al. (2011) found surface turbulent heat fluxes to exceed $400 \mathrm{~W} \mathrm{~m}^{-2}$ during certain events of barrier winds. They pointed out that the magnitude of air-sea heat fluxes during barrier wind events is controlled by the air-sea temperature difference, with high heat fluxes only when the air is significantly colder than the ocean, that is in the presence of an intense CAO.

Following the approach by Papritz and Spengler (2016), I make use of kinematic trajectories that sample wintertime $\mathrm{CAO}$ airmasses in the Irminger Sea to

1. characterise the synoptic environments in which westerly and easterly CAOs form;

2. analyse the Lagrangian evolution of characteristic properties of these airmasses; and

3. quantify the amount of heat extracted from the ocean.

The article is structured as follows: In section 2 I outline the method to obtain the trajectory data set, followed in section 3 by three case studies of CAOs in the Irminger Sea, two of which are of the easterly and one of the westerly CAO type. These case studies are followed in section 4 by a climatological account of the characteristics of Irminger Sea CAO airmasses, an analysis of the synoptic environments in which they form, and a quantification of the sensible and latent heat extracted from the ocean by the CAO airmasses. I conclude with a synthesis of the results in section 5 . 


\section{Methodology}

\subsection{Reanalysis and cyclone data sets}

The analyses presented in this study are based on the Interim reanalysis (ERAInterim) from the European Centre for Medium-Range Weather Forecasts (ECMWF; Dee et al., 2011) for extended winters (November-April) in the period 1979 to 2014. The data is available at 6-hourly temporal resolution and on 60 vertical levels. In the horizontal it is interpolated from the original T255 spectral resolution to a $1^{\circ} \times 1^{\circ}$ longitude-latitude grid. Surface turbulent heat fluxes are obtained from model forecast steps 9 to 21 and averaged over 6-hourly windows centred on synoptic times.

In order to quantify how often cyclones are involved in CAO formation, I make use of the sea level pressure based cyclone identification method by Wernli and Schwierz (2006). This method yields for each time step a binary field indicating at each grid point whether it is affected by the presence of a cyclone or not. Thereby, the area affected by a cyclone is determined by the outermost closed contour of sea level pressure surrounding one or several pressure minima but no maxima. Furthermore, the maximum contour length is limited to 7'500 km. Averaging of the binary cyclone fields over a specific set of time steps yields the respective frequency of cyclones. In addition, cyclone centers, each defined as the deepest minimum within a sea level pressure contour, are tracked using an updated version of the tracking algorithm by Wernli and Schwierz (2006). I use these cyclone tracks to identify cyclogenesis events in the Irminger Sea. 


\subsection{Compilation of CAO trajectory data set}

Kinematic trajectories are calculated with the aid of the LAGRangian ANalysis TOol (LAGRANTO; Sprenger and Wernli, 2015), which uses the three dimensional winds from ERA-Interim as input. The starting region of the trajectories encompasses the waters in the lee of Greenland that extend from Cape Farewell to Denmark Strait and Iceland (cf. Fig. 1). Trajectory starting positions are defined on a regular grid with $80 \mathrm{~km} \times 80 \mathrm{~km}$ horizontal grid spacing on 21 equidistant vertical levels ranging from $1000 \mathrm{hPa}$ to $500 \mathrm{hPa}$. Accordingly, each trajectory represents a mass of $\sim 1.6 \cdot 10^{12} \mathrm{~kg}$.

The compilation of the trajectory data set is undertaken in three main steps:

1. Initial grid points are defined to comprise all points of the starting grid that lie within the starting area and satisfy $\theta_{\mathrm{SKT}}-\theta>4 \mathrm{~K}$, where $\theta$ and $\theta_{\mathrm{SKT}}$ denote potential temperature and potential skin temperature, respectively. The initial grid points are further required to be neither covered by land nor sea ice, i.e., fractional land and sea ice cover must be below $50 \%$.

2. Trajectories are calculated from the initial grid points backward in time for a duration of $6 \mathrm{~h}$. If at the previous synoptic time the trajectory is not considered a $\mathrm{CAO}$, i.e., $\theta_{\mathrm{SKT}}-\theta \leq 0 \mathrm{~K}$ at $t=-6 \mathrm{~h}$, the trajectory is retained, otherwise it is discarded. By virtue of this criterion a double sampling of the same CAO airmass by more than one trajectory is avoided.

3. The retained trajectories are extended forward and backward in time to span the time interval $-192 \mathrm{~h} \leq t \leq 144 \mathrm{~h}$, such as to encompass the preconditioning of the CAO airmass, as well as the entire lifetime of the CAO. 
In addition, wind speed, temperature, and surface turbulent heat fluxes are traced along trajectories by interpolating these fields to the respective trajectory positions.

In this study, I only consider trajectories with $\theta_{\mathrm{SKT}}-\theta>4 \mathrm{~K}$ at $t=0 \mathrm{~h}$. Hence, I exclude weak CAO airmasses, which are frequent but have a limited impact on airsea heat exchanges (Papritz et al., 2015; Papritz and Spengler, 2016). A sensitivity analysis revealed that the results presented in this study are rather insensitive to the precise choice of the threshold (not shown). Furthermore, only airmasses associated with the formation of a CAO in the Irminger Sea are included in the analysis, whereas $\mathrm{CAO}$ airmasses satisfying $\theta_{\mathrm{SKT}}-\theta>4 \mathrm{~K}$ elsewhere but being advected into the Irminger Sea are not considered.

Finally, I introduce three notions that will facilitate the subsequent discussion of the results. The time of $\mathrm{CAO}$ formation, i.e., $t=0 \mathrm{~h}$., is refered to as the basetime, and the rate of CAO formation is defined as the number of trajectories newly satisfying $\theta_{\mathrm{SKT}}-\theta>4 \mathrm{~K}$ per 6 hours. Furthermore, the continuous time period beginning at $t=0 \mathrm{~h}$ and for which $\theta_{\mathrm{SKT}}-\theta>0 \mathrm{~K}$ is denoted by the $C A O$ phase of a trajectory.

\section{Case studies}

Here, I will illustrate typical pathways of CAO airmasses and corresponding synoptic situations. To that end, I consider three case studies, a westerly CAO (case A) and two easterly CAOs with differing synoptic situations (cases B and C). I focus on the peak of the events, i.e., the time step when the rate of CAO formation is maximum. For the sake of clarity, I only display trajectories whose basetime 
corresponds to the time of the peak of the event.

\subsection{Case A: 16 February 2005}

In case A the upper-level flow is dominated by the passage of an upper-level trough over southern Greenland, which induces lee cyclogenesis (Fig. 2a). Furthermore, an anti-cyclone is located west of the British Isles. Two days before CAO formation, most of the air parcels are located south-west of Baffin Island, which are then advected into the Labrador Sea below the upper-level trough. As the trough crosses Greenland, they ascend on its rearward flank over southern Greenland, and subsequently descend along the steep coastline into the Irminger Sea. As the air parcels flow over southern Greenland, their trajectory shows typical features of rotational flows past large mountains (cf. Petersen et al., 2003), namely deceleration and poleward deflection on the upstream side, decreasing vorticity during ascent with anti-cyclonic curvature on the mountain crest, and increasing vorticity as they descend.

After $\mathrm{CAO}$ formation, the strong pressure gradient over the Irminger and Norwegian seas, established by the anti-cyclone over the British Isles and the leecyclone, causes a rapid advection of the air parcels towards the coast of middle and northern Norway, whereby the air-parcel trajectories remain coherent (Fig. 2b). As a consequence of the north-eastward translation of the lee cyclone towards Svalbard, a substantial fraction of the air parcels is caught by the cyclonic flow and advected into the interior Arctic and the Barents Sea. 


\subsection{Case B: 9 December 1981}

In case B an intense and persistent anti-cyclone centered over Greenland leads to a coherent, deep transport of cold airmasses from Fram Strait along Greenland's east coast into the Irminger Sea (Fig. 2c). The trajectories show that the drainage of radiatively cooled airmasses from northern Greenland enhances this cold air flow. A number of air parcels overflow Iceland prior to CAO formation. Accordingly, CAO formation takes place over Denmark Strait and off the south-western coast of Iceland.

A peculiarity of the flow configuration is a saddle point in sea level pressure located over the central North Atlantic, which occurs because the anti-cyclone over Greenland is flanked by cyclonic circulations; specifically at peak time a cyclonic disturbance is located close to Newfoundland and a broad trough is found over Scandinavia (Fig. 2c). Consequently, a bifurcation occurs and the air parcels are diverted in opposite directions after CAO formation (Fig. 2d). A bundle of trajectories reaches Canada north of Newfoundland, whereas another bundle is directed towards the British Isles.

\subsection{Case C: 29 December 2012}

In contrast to case B, the anti-cyclone over Greenland is much less pronounced in case C. Instead, the dominating large-scale features are upper-level wave breaking over the eastern North Atlantic and an associated deep cyclone with its center located south-east of Iceland (Fig. 2e). The cyclonic circulation gives rise to strong north-easterlies over Denmark Strait, conducive for barrier winds (Harden et al., 2011), whereas further north along Greenland's coast, northerlies are restricted 
to the coastal areas. The spatial distribution of CAO air parcels prior to CAO formation shows large scatter and the trajectories are less coherent than in case B. Three main bundles of air parcels are discernible: first, the main bundle of air parcels originates in the Arctic and over northern Greenland, with trajectories akin to those of case B, but restricted to the vicinity of coastal Greenland; second, cold drainage flows from south-eastern Greenland descend into the Irminger Sea near Denmark Strait; and third, a bundle of marine air parcels is advected into the Irminger Sea by the cyclonic circulation over the Nordic Seas. After CAO formation, the air parcels contribute to the cold sector of the cyclone and they are advected towards Scotland and southern Norway (Fig. 2f). Furthermore, a number of air parcels also recirculate into the Nordic Seas.

\section{Climatological perspective on Irminger Sea CAOs}

The three cases of Irminger Sea CAOs presented in the previous section are archetypal, as I aim to corroborate in the following from a climatological perspective. I do this by examining the climatological pathways and Lagrangian characteristics of Irminger Sea CAO airmasses and by investigating the composite large-scale environments in which these CAOs form.

\subsection{Westerly and easterly CAO trajectories}

I stratify CAO trajectories into westerly and easterly ones according to longitude two days prior to CAO formation, i.e., at $t=-48 \mathrm{~h}$. If at this time a specific trajectory is located to the west (east) of Cape Farewell, $43^{\circ} \mathrm{W}$, it is considered a westerly (easterly) trajectory. This criterion provides a clear-cut separation of 
trajectories following the westerly and easterly pathways, respectively, as is confirmed by maps of the climatological mean horizontal mass fluxes (Figs. 3a, b). Note that the horizontal mass flux associated with a single trajectory is given by $M \cdot \mathbf{u}$, where $M \approx 1.6 \cdot 10^{12} \mathrm{~kg}$ denotes its mass and $\mathbf{u}$ its horizontal wind vector. By virtue of the hydrostatic relation, the horizontal mass fluxes can be expressed in units of hPa ms s${ }^{-1}$.

Westerly CAO airmasses have their origin over Labrador and Baffin Island, subsequently move into the Labrador Sea and then overflow southern Greenland with CAO formation along Greenland's south-eastern coast (Fig. 3a). Undulations of mass flux vectors over and around Greenland hint at similar air parcel trajectories in the climatology as in case A, reflecting changes of relative vorticity associated with the overflow of Greenland. On the downslope side of Greenland, the mass fluxes are most intense in the Ammasslik area and over the southernmost tip of Greenland.

Easterly CAO airmasses originate largely in the interior Arctic but are enhanced by cold drainage flows from northeastern Greenland, as well as by cold airmasses from the Barents Sea (Fig. 3a). Airmasses originating over the Nordic Seas, as in case $\mathrm{C}$, however, are rather atypical. In contrast to westerly CAOs, the formation of easterly CAOs occurs in the northern parts of the Irminger Sea, namely over Denmark Strait - as off-ice flow - as well as off the coast of southwestern Iceland (Fig. 3b).

After CAO formation, westerly CAO airmasses are advected eastwards towards the British Isles, Norway, as well as the Barents Sea (Fig. 3c). For easterly CAOs, however, the climatology shows a splitting of CAO airmass fluxes, towards the British Isles and the southern Labrador Sea, but with the more intense 
fluxes directed towards the east (Fig. 3d). Furthermore, easterly CAO airmasses are transported less far to the north than westerly airmasses.

\subsection{Characteristics of CAO airmasses}

Figure 4a shows the pressure distribution of westerly and easterly CAO trajectories. About $50 \%$ of the westerly $\mathrm{CAO}$ trajectories do not show substantial ascent before descending into the Irminger Sea. These non-ascending trajectories originate in the free troposphere above the inversion layer of a CAO airmass in the Labrador Sea. Interestingly, also about $25 \%$ of the easterly CAO trajectories descend by more than $200 \mathrm{hPa}$ with no previous ascent before. They largely represent radiatively cooled airmasses originating from the plateau of northern Greenland.

High wind speeds strongly enhance surface fluxes of sensible and latent heat. Given the prevalence of high wind speed events in the Irminger Sea, it is, therefore, interesting to look at the distribution of wind speeds, as evident from the kinetic energy distribution, among westerly and easterly CAO trajectories. Westerly CAO trajectories are accelerated while they descend into the Irminger Sea (Fig. 4b). Doyle and Shapiro (1999) suggested that this acceleration is owed to Bernoulli conservation. However, it is conceivable that, for example, the downward mixing of momentum contributes too. The maximum $90^{\text {th }}$-percentile specific kinetic energy amounts to about $330 \mathrm{~m}^{2} \mathrm{~s}^{-2}$, corresponding to $\approx 26 \mathrm{~m} \mathrm{~s}^{-1}-\mathrm{a}$ typical value for westerly tip jets (Våge et al., 2009a). High wind speeds among easterly CAO trajectories, in contrast, are the result of barrier flow (cf. Harden et al., 2011). The highest median and $75^{\text {th }}$-percentile specific kinetic energy 
among easterly CAO trajectories remain below those of westerly CAOs, whereas the $90^{\text {th }}$-percentile is almost of the same magnitude as for westerly CAOs. It is noteworthy that in both categories the highest specific kinetic energy is observed at the time of or immediately after $\mathrm{CAO}$ formation, indicating that high wind speeds enhance air-sea heat exchanges in these CAO airmasses.

The contributions of diabatic heating and cooling, and adiabatic temperature changes associated with vertical motion to the thermodynamic evolution of CAO airmasses can be investigated via a potential temperature - temperature $(\theta-\mathrm{T})$ diagram (Fig. 5). To facilitate the comparison of temperatures and relative temperature changes for different CAO airmasses, I display the diagrams both in terms of absolute (Fig. 5a) and relative values (Fig. 5b). In addition, I divide westerly CAO trajectories into subsets of ascending and non-ascending trajectories owing to their spread in the vertical before crossing Greenland. Trajectories with a pressure at $t=-48 \mathrm{~h}$ above and below the median among all westerly CAO trajectories are considered as ascending and non-ascending, respectively.

Ascending westerly CAO trajectories are cooled diabatically until about $36 \mathrm{~h}$ before CAO formation. Subsequently, the trajectories are exposed to open ocean in the Labrador Sea. Thereby, the positive air-sea potential temperature difference results in diabatic warming due to intense surface sensible heat fluxes, and, provided sufficient uptake of moisture, the release of latent heat as the trajectories ascend over Greenland. The increase of temperature associated with diabatic warming, however, is overcompensated by adiabatic cooling due to ascent. Nonascending trajectories, in contrast, are initially potentially warmer and undergo substantial diabatic cooling until they begin to descend about $12 \mathrm{~h}$ prior to CAO formation. As the trajectories are located in the free troposphere, both radiation 
and evaporation at the top of a cloud layer are processes that can account for the diabatic cooling. Temperature increases by about $18 \mathrm{~K}$ in the median as the trajectories descend in the lee of Greenland.

Initially potentially colder than non-ascending westerly $\mathrm{CAO}$ trajectories, easterly CAO trajectories are subject to less diabatic cooling. Nevertheless, they show a temperature increase of about $10 \mathrm{~K}$ - a signature of descent during the $48 \mathrm{~h}$ prior to CAO formation. This warming is due to airmasses drained from northern Greenland, which merge with the southbound stream of CAO airmasses along Greenland's eastern coast. However, diabatic warming also contributes slightly to this temperature increase, indicating that some trajectories are exposed to open ocean in the Greenland and Iceland seas, and hence to surface heat fluxes already before $\mathrm{CAO}$ formation in the Irminger Sea.

During the $\mathrm{CAO}$ phase, which in the median lasts about $30 \mathrm{~h}$ for westerly and $42 \mathrm{~h}$ for easterly CAOs, trajectories warm substantially due to surface sensible heat fluxes and latent heat release. While westerly and easterly CAO trajectories are warmed at similar rates during the first $24 \mathrm{~h}$ after CAO formation, easterly CAO trajectories are subject to more diabatic warming over the entire CAO phase than westerly ones. Furthermore, ascending westerly CAO trajectories are heated more than non-ascending ones due to lower potential temperature at $t=0 \mathrm{~h}$, and hence stronger surface sensible heat fluxes. As I will discuss later, there are differences in the $\theta$-T curves of easterly $\mathrm{CAO}$ trajectories depending on the precise pathways of the airmasses, and therefore the synoptic environment. 


\subsection{Identification of CAO events}

Figure 6a shows an example timeseries of the rates of CAO formation for extended winter 2009 / 2010. Several periods of continuously enhanced formation rates are evident, each of them showing one or several pronounced peaks indicating CAO events. Specifically, I define CAO events as follows: First, local maxima of the formation rate timeseries exceeding the $95^{\text {th }}$-percentile in the study period are identified. The $95^{\text {th }}$-percentile threshold ensures that only particularly intense $\mathrm{CAO}$ events are selected. Second, several such maxima occuring within a 2-day window are clustered on the most intense maximum with the weaker ones being removed. The remaining maxima define the $\mathrm{CAO}$ events.

The number of CAO events in the Irminger Sea increases gradually during the first three winter months (Fig. 6c). It remains high until March and falls off steeply in April. Westerly CAOs are most frequent in February, the coldest month of the year, whereas easterly CAOs are most frequent in January and March with a minimum in February. It is important to note that, owing to the large interannual variability, this February minimum is not a statistically robust feature and a corroboration would require longer timeseries. In fact, only 12 out of 35 winters feature a lower number of events in February than in both January and March.

On average there are 15.3 so defined CAO events per extended winter, whereoff 7.3 are of the westerly and 8 of the easterly type, yielding a total of 254 westerly and 280 easterly CAO events in the study period. The inter-annual variability is substantial, however, with a minimum of 6 events in winters 1984 / 1985 and 2002 / 2003, and a maximum of 27 events in 1982 / 1983 (Fig. 6b). The yearly numbers of westerly and easterly events are only weakly correlated $(r=0.34)$, 
indicating that the formation of westerly and easterly CAOs is subject to very different large-scale conditions.

The North Atlantic Oscillation (NAO), characterized by the pressure difference between Stykkisholmur (Iceland) and Lisbon (Portugal), is the principal mode of large-scale variability over the North Atlantic (e.g., Wanner et al., 2001), potentially with a strong influence on the formation of CAOs in the Irminger Sea. For example, a case study of the negative NAO winter 2010 suggests that the NAO exerts some control on the occurrence of CAOs in the Labrador and Irminger seas via its association with anomalous cyclone frequency near Iceland (Woollings et al., 2016). Using the normalized NAO index by Hurrell (1995), the number of westerly CAO events per extended winter is weakly correlated with the NAO index averaged over the same months $(r=0.41)$. This suggests that the formation of westerly CAOs is more frequent in winters with an enhanced cyclone activity near Iceland and in the Irminger Sea. In contrast, no substantial correlation exists for easterly CAOs $(r=0.17)$, indicating that modes of variability other than the NAO, such as, for example, the Iceland - Lofoten dipole in cyclone activity (Jahnke-Bornemann and Brümmer, 2009) play a more important role for these. These rather modest and low correlations for westerly and easterly CAOs, respectively, are in contrast to the comparatively high correlations of a CAO index with the NAO (up to $r=0.7$ in the western Irminger Sea) as found by Kolstad et al. (2009). However, their analysis indicates somewhat weaker correlations closer to Denmark Strait, the preferred formation region of easterly CAOs. Furthermore, it is likely that weaker CAOs than the events considered here, are less dependent on modes of variability other than the NAO that favor the meridional, long-range transport of very cold Arctic airmasses. 


\subsection{Synoptic environments}

\subsubsection{Composites}

In order to elucidate the synoptic environments in which westerly and easterly CAOs form, I consider lag composites of $500 \mathrm{hPa}$ geopotential height and sea level pressure for westerly (Figs. 7a - e) and easterly (Figs. 7f - k) CAO events.

One day before the peak of a westerly CAO event, the center of an upper-level trough is located to the west of Greenland (Fig. 7a). As in case A, the upperlevel trough subsequently extends over the tip of southern Greenland, providing favourable conditions for lee cyclogenesis or the intensification of pre-existing cyclones (Figs. 7b, c). In fact, $24 \%$ of the westerly CAO events feature cyclogenesis during the day prior to the peak of the event, whereby the respective cyclone centers are required to be located in the Irminger Sea box (cf. green box Fig. 3). This percentage increases to about $30 \%$ when the box is enlarged by $4^{\circ}$ to the north.

In association with the upper-level trough, strong westerly winds prevail over southern Greenland at the $500 \mathrm{hPa}$ level between $-12 \mathrm{~h}$ until the peak of the event (Figs. $7 \mathrm{~b}, \mathrm{c}$ ). These winds are crucial in the advection of the CAO airmasses across southern Greenland. The CAO airmasses then descend on the south-western flank of the lee cyclone into the Irminger Sea, whereby they can accelerate considerably. After the peak of the CAO event, the westerly winds over southern Greenland cease and the center of the lee cyclone translates to the north-east of Iceland (Figs. 7d, e). Thereby, a strong pressure gradient persists to the south of the cyclone center, which gives rise to the rapid eastward advection of the CAO airmasses, in particular towards the coast of Norway.

Prior to easterly CAO events high pressure prevails in the Arctic and over 
northern Greenland (Fig. 7f). Furthermore, at lag -24h two low pressure centres are found in the north-eastern North Atlantic: one to the south of Iceland and a second near the Lofoten archipelago. The anti-cyclonic flow over Greenland and the weak pressure difference between Iceland and the Lofoten archipelago favour northerly winds along most of Greenland's eastern coast. Hence, this configuration is conducive for the long-range transport of Arctic airmasses from Fram Strait to Denmark Strait.

Towards the peak of the CAO event, the low south of Iceland translates to the south-east of Iceland, thereby establishing a strong pressure gradient over Denmark Strait, which is amplified by the barrier effect (Figs. 7g, h). This is in line with high wind speeds found along $\mathrm{CAO}$ trajectories from the time of $\mathrm{CAO}$ formation onward (cf. section 4.2). Subsequently, the center of the low translates further into the Norwegian Sea (Figs. 7i, k).

The synoptic configuration of the flow over the Nordic Seas in the aftermath of a westerly $\mathrm{CAO}$ is favorable for the long-range transport of cold airmasses from Fram Strait southward (cf. Figs. 7d, e). Consequently, 47 (18.5\%) of the westerly $\mathrm{CAO}$ events are succeeded by an easterly event within $48 \mathrm{~h}$ of the former. In contrast, only $19(6.8 \%)$ of the easterly events are followed by a westerly event.

\subsubsection{Role of anti-cyclones and cyclones in easterly CAO formation}

As suggested by the case studies, easterly CAOs can occur in the presence of an anti-cyclone over Greenland (case B), or one or multiple cyclones in the Nordic Seas (case C). Furthermore, the absence of a pronounced upper-level ridge over Greenland in the composites (Figs. 7f-k) indicates that anti-cyclonic flow over Greenland is not present in all cases. 
In order to stratify the easterly $\mathrm{CAO}$ cases according to the anti-cyclonicity of the flow over and around Greenland, I define a Northern Greenland Blocking Index (NGBI). To that end, I extract the timeseries of the area averaged deviation of $500 \mathrm{hPa}$ geopotential height from the zonal mean with the area average taken over the region $80^{\circ} \mathrm{W}-20^{\circ} \mathrm{W}, 68^{\circ} \mathrm{N}-80^{\circ} \mathrm{N}$ (cf. gray box Fig. 9). The NGBI is obtained from normalizing this timeseries by its standard deviation. This index deviates in two important aspects from indices commonly used to characterise Greenland blocking (e.g., Hanna et al., 2016). First, the area only covers the northern part of Greenland, thereby preventing lee troughs to the south-east of Greenland from polluting the index. The existence of such lee troughs at $500 \mathrm{hPa}$ is evident in the composites of westerly, as well as easterly CAOs (Fig. 7). Second, considering the deviation from the zonal mean ensures that meridional transports are emphasized, whereas zonally uniform states of high or low heights in the latitudinal band of northern Greenland result in neutral values of the index.

The NGBI corresponding to a CAO event is defined as the value of the NGBI at the peak of the event, i.e., at lag $0 \mathrm{~h}$. Figure 8 shows the distribution of the NGBI for westerly and easterly CAOs. The distribution of the NGBI for westerly CAOs is clearly shifted towards negative values compared to climatology - a signature of the trough crossing Greenland prior to the $\mathrm{CAO}$ event. In contrast, the distribution resembles that of the climatology in the case of easterly CAOs, with the exception that tails are wider. This similarity suggests that a continuous spectrum exists that ranges from cases with an anti-cyclone over Greenland only, such as case B, to cases with a trough over Greenland, potentially with one or multiple cyclones in the Nordic Seas.

To quantify how often cyclones are involved in the formation of easterly CAOs, 
I split the cases into terciles according to the NGBI, yielding about 93 cases in each tercile. For each tercile I compile composites of $500 \mathrm{hPa}$ geopotential height and compute the frequency of cyclones at lags $-24 \mathrm{~h}$ and $0 \mathrm{~h}$.

The lower tercile comprises cases with a main trough to the west of Greenland and a secondary trough east of southern Greenland (Fig. 9a). This secondary trough is related to a high frequency of cyclones to the south-east of Iceland with a maximum frequency of about $80 \%$ at lag $0 \mathrm{~h}$. One day prior to the $\mathrm{CAO}$ event local maxima of cyclone frequency are found in the Irminger Sea and off the Lofoten archipelago, akin to the sea level pressure distribution in the composite (Fig. 7f). A similar dipole structure of cyclone frequency at lag $-24 \mathrm{~h}$ is also evident in the middle tercile (Fig. 9b), however, with no significant trough over Greenland. The upper tercile, in contrast, is characterised by a ridge with its axis located over western Greenland, and therefore anti-cyclonic flow over and around Greenland, as well as low cyclone frequencies (Fig. 9c). Within this classification scheme, case study B clearly belongs to the upper tercile, whereas case study C represents an intermediate case with strongly cyclonic flow over the Nordic Seas and weakly anti-cyclonic flow over northern Greenland, hence, corresponding to the middle tercile.

As found in case study B, easterly CAO airmasses can be diverted in opposite directions over the North Atlantic after CAO formation. The CAO airmass fluxes (cf. Fig. 3d) corroborated further that such a splitting is not a peculiarity of this particular case but a climatological feature. A separation of the mass fluxes according to NGBI terciles reveals that a diversion to the west occurs only in the case of strongly anti-cyclonic flow over Greenland, that is for cases in the upper tercile of the NGBI (not shown). For lower and middle terciles with weak anti- 
cyclonicity of the flow over Greenland, however, the CAO airmasses are captured by the cyclonic flow over the Nordic Seas and in consequence they are advected to the east towards the British Isles and Norway.

The thermodynamic evolution of $\mathrm{CAO}$ airmasses prior to $\mathrm{CAO}$ formation is by and large independent of the NGBI, i.e., the relative $\theta-\mathrm{T}$ curves are similar for all terciles (Fig. 5b). After CAO formation, however, the airmasses of the lower tercile experience less diabatic heating and more adiabatic cooling than airmasses of the upper tercile. In fact, the airmasses of the lower tercile undergo an evolution akin to that of westerly CAO airmasses, which is owed to similar synoptic conditions with predominantly cyclonic flow over the Nordic Seas, and hence, similar pathways.

\subsection{Surface turbulent heat fluxes}

Papritz and Spengler (2016) addressed the question of how much sensible and latent heat $\mathrm{CAO}$ airmasses extract from the ocean during the $\mathrm{CAO}$ phase. To that end, they interpolated surface sensible and latent heat fluxes to the trajectory positions and accumulated them over the CAO phase of each trajectory. They found Irminger Sea CAO airmasses to extract substantially more latent heat than CAO airmasses in the Nordic Seas with a comparable air-sea potential temperature difference, a circumstance they attributed to the higher sea surface temperature to which Irminger Sea CAO airmasses are exposed. They found further that the total surface turbulent heat flux of Irminger Sea CAO trajectories is dominated by the latent heat flux, whereas in the Nordic Seas the sensible heat flux typically exceeds the latent heat flux. 
As shown by Papritz et al. (2015), the surface sensible heat flux is proportional to the air-sea potential temperature difference, whereas the latent heat flux saturates for strong air-sea potential temperature difference at a value essentially determined by the sea surface temperature. Furthermore, for a CAO airmass, which is essentially dry at the time of CAO formation, a strongly non-linear relationship exists between the sea surface temperature and the latent heat flux. This non-linearity is owed to the approximately exponential relationship between temperature and saturation vapour pressure following the Clausius - Clapeyron relation. Consequently, the total heat extracted from the ocean by turbulent heat fluxes depends at first order on the initial intensity of the CAO as measured by the air-sea potential temperature difference, as well as the sea surface temperature to which the airmass is exposed (see also Papritz and Spengler (2016) for a more detailed discussion).

I aim here to focus the analysis of Papritz and Spengler (2016) on the Irminger Sea and refine it by quantifying the extraction of heat from the ocean by westerly and easterly CAO airmasses separately (Fig. 10). Westerly and upper tercile easterly CAO trajectories are the coldest in terms of potential temperature (cf. Fig. 5a) and, therefore, feature the strongest air-sea potential temperature difference at $t=0 \mathrm{~h}$ among all trajectory subsets. Thus, they extract the most sensible heat in the median (Fig. 10a). Furthermore, westerly and lower tercile easterly $\mathrm{CAO}$ trajectories follow similar pathways after $\mathrm{CAO}$ formation into the Nordic Seas, where waters are colder than further south. Thus, it is unsurprising that they extract less latent heat than middle and upper tercile easterly CAO trajectories (Fig. 10b), which are exposed to comparatively warmer waters at lower latitudes. In fact, the sea surface temperature is the highest for upper tercile easterly CAO 
trajectories (not shown) and consequently they extract the most latent heat. However, given the strong diversion of these trajectories, the range of sea surface temperatures to which they are exposed is wider than for the other trajectory subsets. Accordingly, the $10^{\text {th }}$ to $90^{\text {th }}$ - percentile range is the largest for this subset. In the sum, the upper tercile easterly CAO trajectories feature the highest integrated turbulent heat fluxes in the median with the largest $10^{\text {th }}$ to $90^{\text {th }}$ - percentile range among all subsets, whereas westerly and lower tercile easterly CAO trajectories extract the least amount of heat (Fig. 10c).

Surface sensible and latent heat fluxes translate into diabatic warming of the CAO airmass via turbulent upward mixing of the heat in the case of sensible heat fluxes and via condensation, deposition, and freezing in the case of latent heat fluxes. Given that the median surface turbulent heat fluxes are the strongest for the upper tercile easterly CAO trajectories, they undergo the most intense diabatic warming, as supported by the $\theta-\mathrm{T}$ curves (Fig. 5b). In contrast, westerly and lower tercile easterly CAO trajectories are heated the least and they undergo a very similar thermodynamic evolution owing to roughly equal amounts of heat input.

\section{Synthesis and concluding remarks}

In this study, I characterised the large-scale synoptic environments favorable for wintertime CAO formation in the Irminger Sea and investigated the pathways of the involved airmasses, as well as their characteristic properties. To this end, I made use of kinematic trajectories, derived from the three dimensional winds in ERA-Interim, to sample Irminger Sea CAO airmasses. 
I identified three distinct synoptic environments conducive for CAO formation in the Irminger Sea. These environments and the associated transport pathways of the airmasses before and after CAO formation are schematically summarised in Fig. 11. Our principal findings in regard of these environments and the properties of the associated CAO airmasses are:

1. In the westerly environment (Fig. 11a), an upper-level trough, with its axis crossing Greenland's plateau, establishes flow towards southern Greenland and strong westerly winds at its crest. Hence, CAO airmasses from the Canadian Arctic, whereof more than $50 \%$ originate in the free troposphere and do not ascend substantially prior to crossing Greenland, are forced to overflow southern Greenland and descend in its lee. The most intense climatological downslope mass fluxes are focused on the Ammassalik region and Greenland's southern tip. Moreover, the eastward motion of the upperlevel trough is conducive for lee cyclogenesis or the intensification of a preexisting cyclone in the lee of Greenland. In fact, cyclone tracks revealed that almost one third of the westerly $\mathrm{CAO}$ events feature lee cyclogenesis. As the lee cyclone propagates into the Nordic Seas, the CAO airmasses are rapidly exported north-eastwards on the cyclone's southern flank.

2. A major fraction of easterly $\mathrm{CAO}$ airmasses originates in the interior Arctic and is transported all the way from Fram Strait along Greenland's eastern coast towards Denmark Strait. In the cyclonic environment (Figs. 11b), this long-range transport is established by one or two sequential extratropical cyclones located ahead of an upper-level trough, whereas in the anti-cyclonic environment (Figs. 11c) the transport is due to anti-cyclonic flow over and 
around Greenland. Contributions from katabatic drainage flows from northern Greenland merge with the southbound flow of barrier-wind enhanced CAO airmasses, whereby in the case of the cyclonic environment, additionally also marine airmasses from the Barents and Nordic seas contribute.

After CAO formation, the airmasses follow a similar pathway as in the westerly environment in the cyclonic case, albeit reaching less far north along the Norwegian coast. In contrast, a bifurcation occurs in the anti-cyclonic case with some of the airmasses not being advected eastwards but towards Newfoundland and Labrador instead.

3. The westerly environment bears similarities to the synoptic configuration identified by Kolstad et al. (2009), whereas the easterly environments are clearly distinct. The cyclonic and anti-cyclonic easterly environments represent limiting cases of an intermediate spectrum with synoptic features common to both environments.

4. The synoptic configuration of the flow over the Nordic Seas in the aftermath of a westerly $\mathrm{CAO}$ event is conducive for the transport of airmasses along Greenland's eastern coast. Consequently, almost $20 \%$ of the westerly CAO events are succeeded by a cyclonic easterly event within $48 \mathrm{~h}$ after the peak of the westerly event.

5. About $10 \%$ of the CAO trajectories experience high wind speeds in excess of $20 \mathrm{~m} \mathrm{~s}^{-1}$ during the CAO phase, which are associated with westerly tip jets in the case of westerly CAOs, and barrier winds in the case of easterly cyclonic CAOs. The intense winds imply a high potential of these airmasses to extract sensible and latent heat from the ocean. 
6. The amount of heat extracted from the ocean, and hence the diabatic temperature increase after $\mathrm{CAO}$ formation, depends not only on the air-sea potential temperature difference at the time of CAO formation, but also on the subsequent pathway of the airmasses, which is set by the respective synoptic environment. Specifically, airmasses associated with easterly anti-cyclonic CAO events extract - when accumulated over the entire CAO phase - the most heat from the ocean, which is due to their exposition to warmer waters along their pathway; this results in the strongest diabatic temperature increase among Irminger Sea CAO airmasses.

The formation of CAOs is closely related to the occurrence of barrier winds. Harden et al. (2011) identified two distinct regimes of barrier winds near Denmark Strait, a cold and a warm regime. Cold barrier winds occur in the presence of a cyclone in the Norwegian Sea prior to the event, which promotes the southward transport of cold airmasses along Greenland's east coast, and the subsequent passage of a cyclone with its core near Iceland, hence, resembling the easterly cyclonic $\mathrm{CAO}$ regime. This indicates that cold barrier winds are closely related to easterly cyclonic CAOs, whereby the barrier flow channels CAO airmasses through Denmark Strait. Interestingly, also the synoptic environments of warm barrier winds and westerly CAOs bear a certain similarity with a cyclone located in the central Irminger Sea. In cases of a concomitant westerly CAO and warm barrier winds, strong north-south contrasts of temperature and air-sea heat flux forcings would ensue over the Irminger Sea, implying high baroclinicity.

The Irminger Sea is an important genesis region for cyclones undergoing strong intensification and propagating north-eastwards into the Nordic Seas (Dacre and Gray, 2009). Here, I have shown that westerly and easterly cyclonic CAO air- 
masses contribute to the cold sector of such cyclones. As surface sensible heating and latent heat release in CAOs enhance lower tropospheric baroclinicity (e.g., Papritz and Spengler, 2015), I hypothesize that a positive feedback exists between $\mathrm{CAO}$ formation and the intensification of cyclones striking the Nordic Seas. Thus, future work should address these feedbacks in numerical process studies, and then assess the relevance of CAO airmasses in enhancing cyclone intensification climatologically.

\section{ACKNOWLEDGEMENTS}

I would like to thank K. Våge (University of Bergen) for helpful discussions and three anonymous reviewers for their insightful comments. Furthermore, I am grateful to the Institute for Atmospheric and Climate Science of ETH Zürich for kindly providing access to their computational resources, and the European Centre for Medium-Range Weather Forecasts for making the ERA-Interim reanalysis available. I acknowledge support by the Swiss National Science Foundation (SNSF), grant P2EZP2_162267. 


\section{References}

Buckley, M. W., and J. Marshall, 2016: Observations, inferences, and mechanisms of atlantic meridional overturning circulation variability: A review. Rev. Geophys., 54, 5-63, doi:10.1002/2015RG000493.

Dacre, H. F., and S. L. Gray, 2009: The spatial distribution and evolution characteristics of North Atlantic cyclones. Mon. Wea. Rev., 137, 99-115, doi: 10.1175/2008MWR2491.1.

Dee, D., and Coauthors, 2011: The ERA-Interim reanalysis: configuration and performance of the data assimilation system. Quart. J. Roy. Meteor. Soc., 137, 553-597, doi:10.1002/qj.828.

Doyle, J. D., and M. A. Shapiro, 1999: Flow response to large-scale topography: The Greenland tip jet. Tellus, 51A, 728-748, doi:10.1034/j.1600-0870.1996. 00014.x.

Hanna, E., T. E. Cropper, R. J. Hall, and J. Cappelen, 2016: Greenland Blocking Index 1851-2015: a regional climate change signal. Int. J. Climatol., 36, 4847 - 4861, doi:10.1002/joc.4673.

Harden, B. E., and I. A. Renfrew, 2012: On the spatial distribution of high winds off southeast Greenland. Geophys. Res. Lett., 39, L14 806, doi:10.1029/ 2012GL052245.

Harden, B. E., I. A. Renfrew, and G. N. Petersen, 2011: A climatology of wintertime barrier winds off southeast Greenland. J. Climate, 24, 4701-4717, doi: 10.1175/2011JCLI4113.1. 
Heinemann, G., and T. Klein, 2002: Modelling and observations of the katabatic flow dynamics over Greenland. Tellus A, 54, 542-554, doi:10.1034/j. 1600-0870.2002.201401.x.

Hurrell, J. W., 1995: Decadal trends in the North Atlantic Oscillation: Regional temperatures and precipitation. Science, 269, 676-679, doi:10.1126/science. 269.5224.676.

Jahnke-Bornemann, A., and B. Brümmer, 2009: The Iceland-Lofotes pressure difference: different states of the North Atlantic low-pressure zone. Tellus A, 61, 466-475, doi:10.1111/j.1600-0870.2009.00401.x.

Kolstad, E. W., T. J. Bracegirdle, and I. A. Seierstad, 2009: Marine cold-air outbreaks in the North Atlantic: temporal distribution and associations with large-scale atmospheric circulation. Clim. Dyn., 33, 187-197, doi:10.1007/ s00382-008-0431-5.

Moore, G. W. K., R. S. Pickart, and I. A. Renfrew, 2008: Buoy observations from the windiest location in the world ocean, Cape Farewell, Greenland. Geophys. Res. Lett., 35, L18 802, doi:10.1029/2008GL034845.

Moore, G. W. K., and I. A. Renfrew, 2005: Tip jets and barrier winds: A QuikSCAT climatology of high wind speed events around Greenland. J. Climate, 18, 3713-3725, doi:10.1175/JCLI3455.1.

Nansen, F., 1912: Das Bodenwasser und die Abkühlung des Meeres. Internationale Revue der Gesamten Hydrobiologie und Hydrographie, 5, 1-42.

Oltmanns, M., F. Straneo, G. W. K. Moore, and S. H. Mernild, 2014: Strong 
downslope wind events in Ammassalik, southeast Greenland. J. Climate, 27, 977-993, doi:10.1175/JCLI-D-13-00067.1.

Papritz, L., S. Pfahl, H. Sodemann, and H. Wernli, 2015: A climatology of cold air outbreaks and their impact on air-sea heat fluxes in the high-latitude South Pacific. J. Climate, 28, 342-364, doi:10.1175/JCLI-D-14-00482.1.

Papritz, L., and T. Spengler, 2015: Climatological analysis of the slope of isentropic surfaces and its tendencies over the North Atlantic. Quart. J. Roy. Meteor. Soc., 141, 3226-3238, doi:10.1002/qj.2605.

Papritz, L., and T. Spengler, 2016: A Lagrangian climatology of wintertime cold air outbreaks in the Irminger and Nordic seas and their role in shaping air-sea heat fluxes. J. Climate, in review.

Petersen, G. N., H. Olafsson, and J. E. Kristjansson, 2003: Flow in the lee of idealized mountains and Greenland. J. Atmos. Sci., 60, 2183-2195, doi: 10.1175/1520-0469(2003)060〈2183:FITLOI $>2.0 . C O ; 2$.

Petersen, G. N., I. A. Renfrew, and G. W. K. Moore, 2009: An overview of barrier winds off southeastern Greenland during the Greenland Flow Distortion experiment. Quart. J. Roy. Meteor. Soc., 135, 1950-1967, doi:10.1002/qj.455.

Pickart, R. S., M. A. Spall, M. H. Ribergaard, G. W. K. Moore, and R. F. Milliff, 2003a: Deep convection in the Irminger Sea forced by the Greenland tip jet. Nature, 424, 152-156, doi:10.1038/nature01729.

Pickart, R. S., F. Straneo, and G. W. K. Moore, 2003b: Is Labrador Sea wa- 
ter formed in the Irminger basin? Deep Sea Res. I, 50, 23-52, doi:10.1016/ S0967-0637(02)00134-6.

Sampe, T., and S.-P. Xie, 2007: Mapping high sea winds from space: a global climatology. Bull. Amer. Meteor. Soc., 88, 1965-1978, doi:10.1175/ BAMS-88-12-1965.

Sprenger, M., and H. Wernli, 2015: The Lagrangian analysis tool LAGRANTO - version 2.0. Geosci. Model Dev., 8, 1893-1943, doi:10.5194/ gmdd-8-1893-2015.

Våge, K., T. Spengler, H. C. Davies, and R. S. Pickart, 2009a: Multi-event analysis of the westerly Greenland tip jet based upon 45 winters in ERA-40. Quart. J. Roy. Meteor. Soc., 135, 1999-2011, doi:10.1002/qj.488.

Våge, K., and Coauthors, 2009b: Surprising return of deep convection to the subpolar North Atlantic Ocean in winter 2007-2008. Nat. Geosci., 2, 67-72, doi:10.1038/NGEO382.

Våge, K., and Coauthors, 2011: The Irminger Gyre: circulation, convection, and interannual variability. Deep Sea Res. I, 58, 590-614, doi:10.1016/j.dsr.2011. 03.001 .

Wanner, H., S. Brönnimann, C. Casty, D. Gyalistras, J. Luterbacher, C. Schmutz, D. B. Stephenson, and E. Xoplaki, 2001: North Atlantic Oscillation - Concepts And Studies. Surv. Geophys., 22, 321-381, doi:10.1023/A:1014217317898.

Wernli, H., and C. Schwierz, 2006: Surface cyclones in the ERA-40 dataset (1958- 
2001). Part I: Novel identification method and global climatology. J. Atmos. Sci., 63, 2486-2507, doi:10.1175/JAS3766.1.

Woollings, T., L. Papritz, C. Mbengue, and T. Spengler, 2016: Diabatic heating and jet stream shifts: A case study of the 2010 negative North Atlantic Oscillation winter. Geophys. Res. Lett., 43, 9994-10 002, doi:10.1002/2016GL070146. 


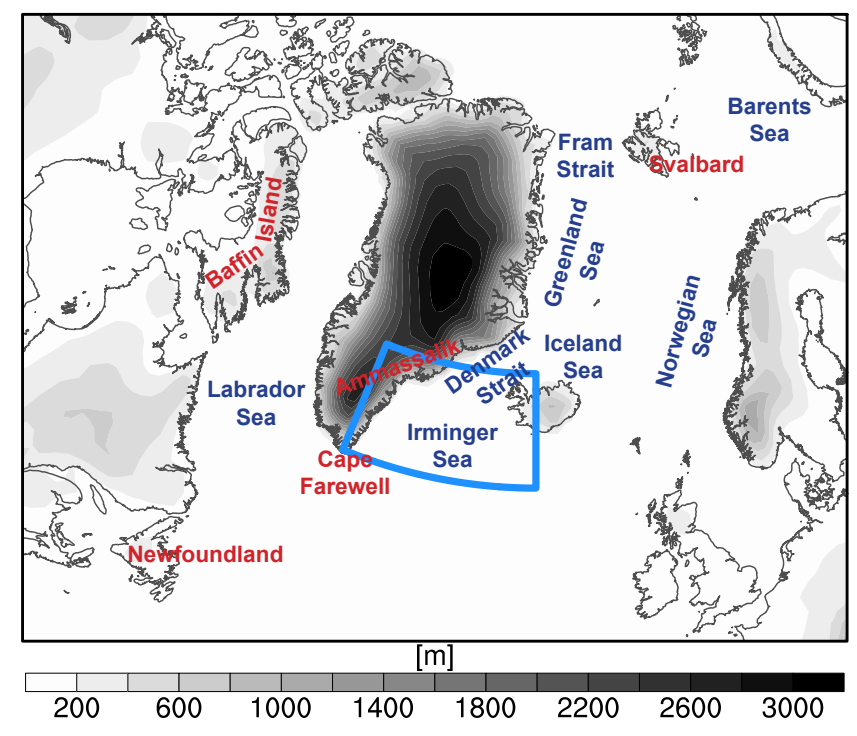

Figure 1: Location names and topography of the study region as represented in ERA-Interim. The blue box shows the starting region for the trajectories. 
a) 00 UTC 16 Feb 2005

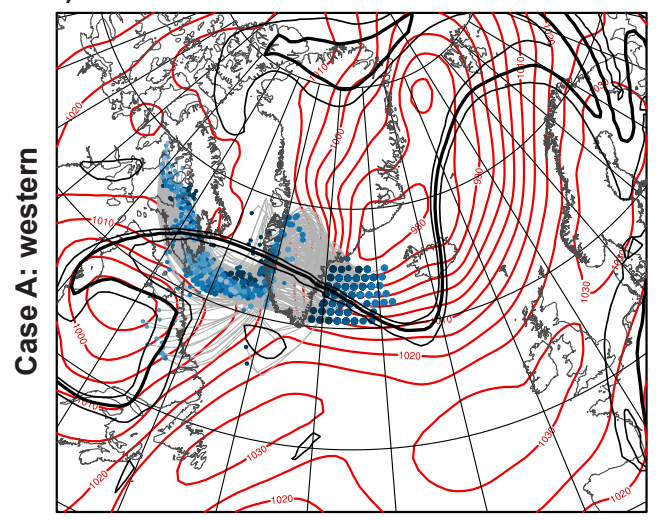

c) 00 UTC 09 Dec 1981

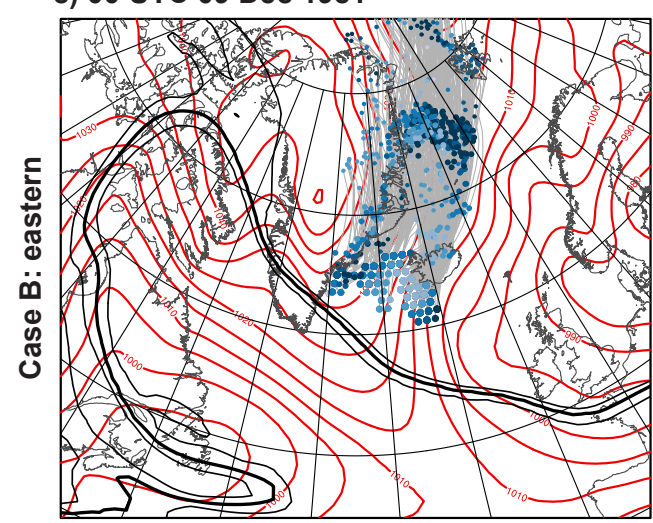

e) 06 UTC 29 Dec 2012

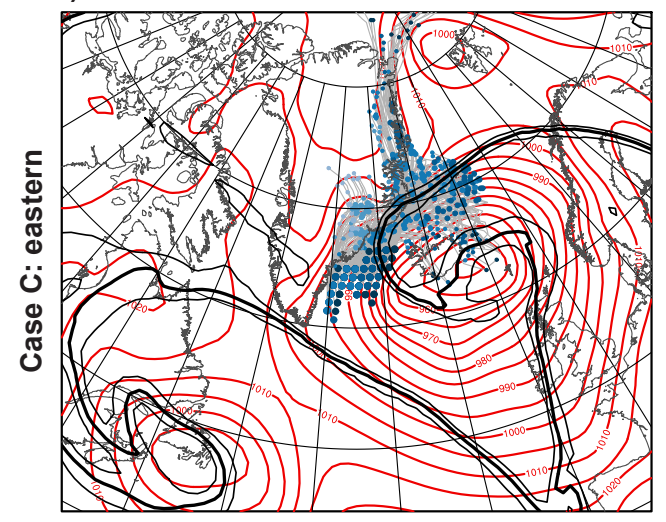

b) 00 UTC 18 Feb 2005

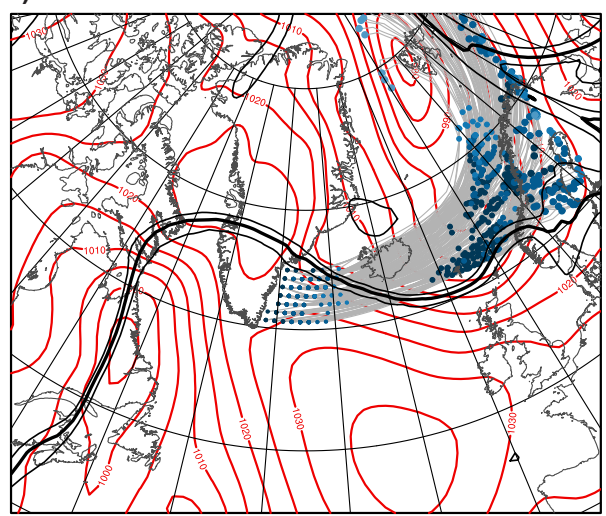

d) 00 UTC 11 Dec 1981

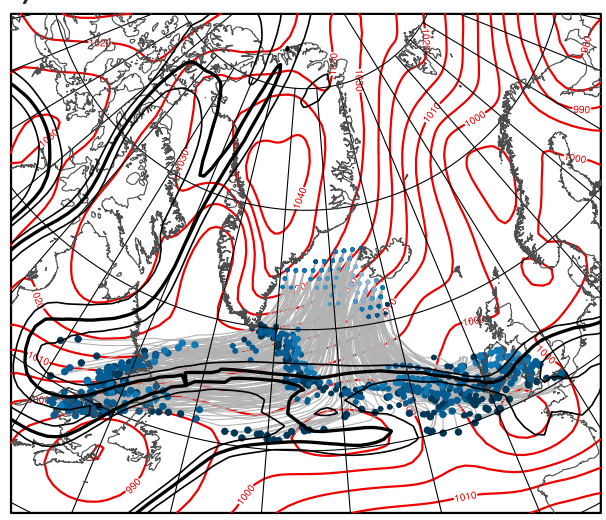

f) 06 UTC 31 Dec 2012

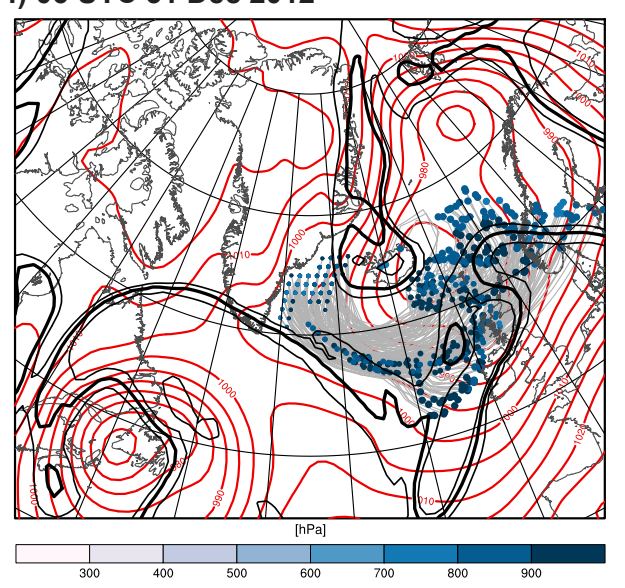

Figure 2: Synoptic configurations for selected westerly (A) and easterly (B, C) CAO events. Shown are sea level pressure in intervals of $5 \mathrm{hPa}$ (red) and PV on the $310 \mathrm{~K}$ isentropic surface from 1 pvu to 3 pvu in intervals of 1 pvu (black, 2 pvu line bold) (a, c, e) at the peak of the events and (b, d, f) 2 days after (cf. dates at the top of each panel). CAO trajectories in the time interval (a, c, e) $-48 \mathrm{~h} \leq t \leq 0 \mathrm{~h}$ and (b, d, f) $0 \mathrm{~h} \leq t \leq 48 \mathrm{~h}$ are shown in gray with dots at the beginning (small dots), middle (medium dots), and end (layge dots) of the respective time intervals. Colors indicate the pressure of the trajectories at the respective times. Note that only trajectories are shown with their basetime corresponding to the peak of the event. 

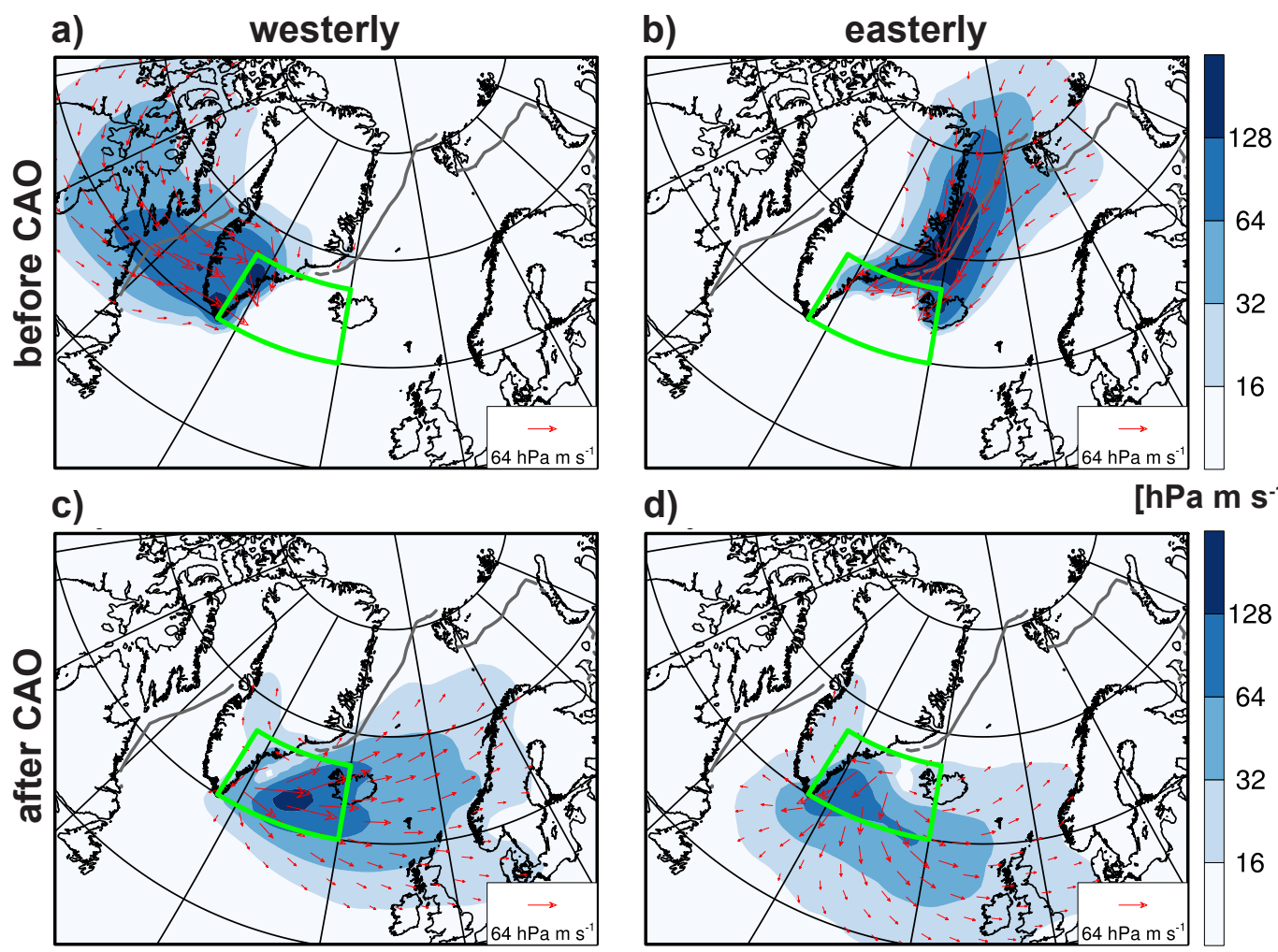

d)

[hPa m s$\left.{ }^{-1}\right]$

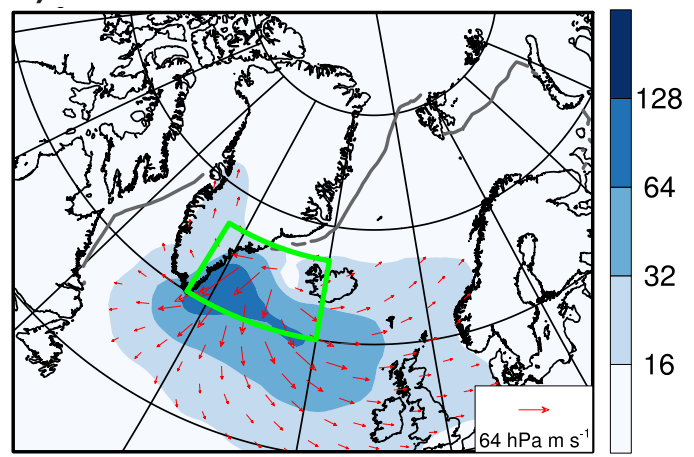

Figure 3: Mean horizontal mass fluxes (vectors) and their magnitude (shading) associated with westerly (a, c) and easterly $(\mathrm{b}, \mathrm{d}) \mathrm{CAO}$ trajectories $(\mathrm{a}, \mathrm{b})$ prior to $(-96 \mathrm{~h} \leq t<0 \mathrm{~h})$ and $(\mathrm{c}, \mathrm{d})$ after $(0 \mathrm{~h} \leq t \leq 96 \mathrm{~h}) \mathrm{CAO}$ formation. The green box outlines the CAO formation area from which backward and forward trajectories are started. The gray contour indicates the sea ice edge $(50 \%$ sea ice concentration). 

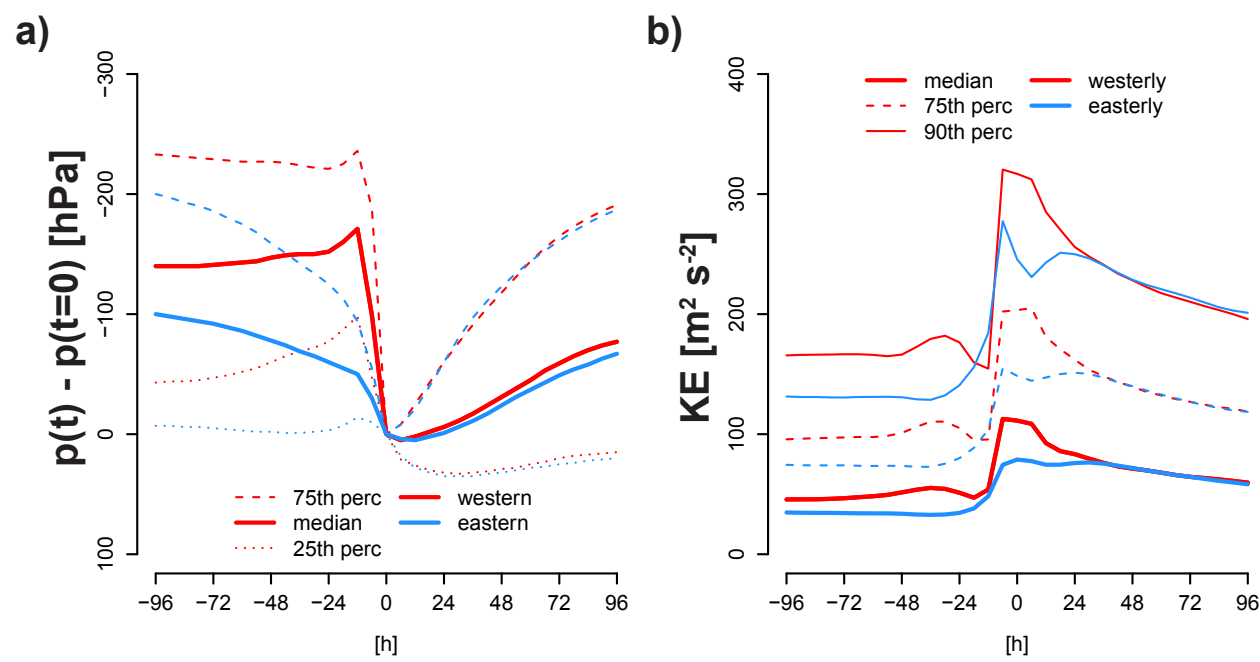

Figure 4: Evolution of (a) pressure relative to the time of CAO formation $(t=$ $0 \mathrm{~h}$ ), and (b) specific kinetic energy for CAO trajectories following the westerly (red) and easterly (blue) pathways. Shown are for (a) the $25^{\text {th }}$-percentile (dotted), the median (solid), and the $75^{\text {th }}$-percentile (dashed), and for (b) the median (solid), the $75^{\text {th }}$-percentile (dashed), and the $90^{\text {th }}$-percentile (thin solid). 

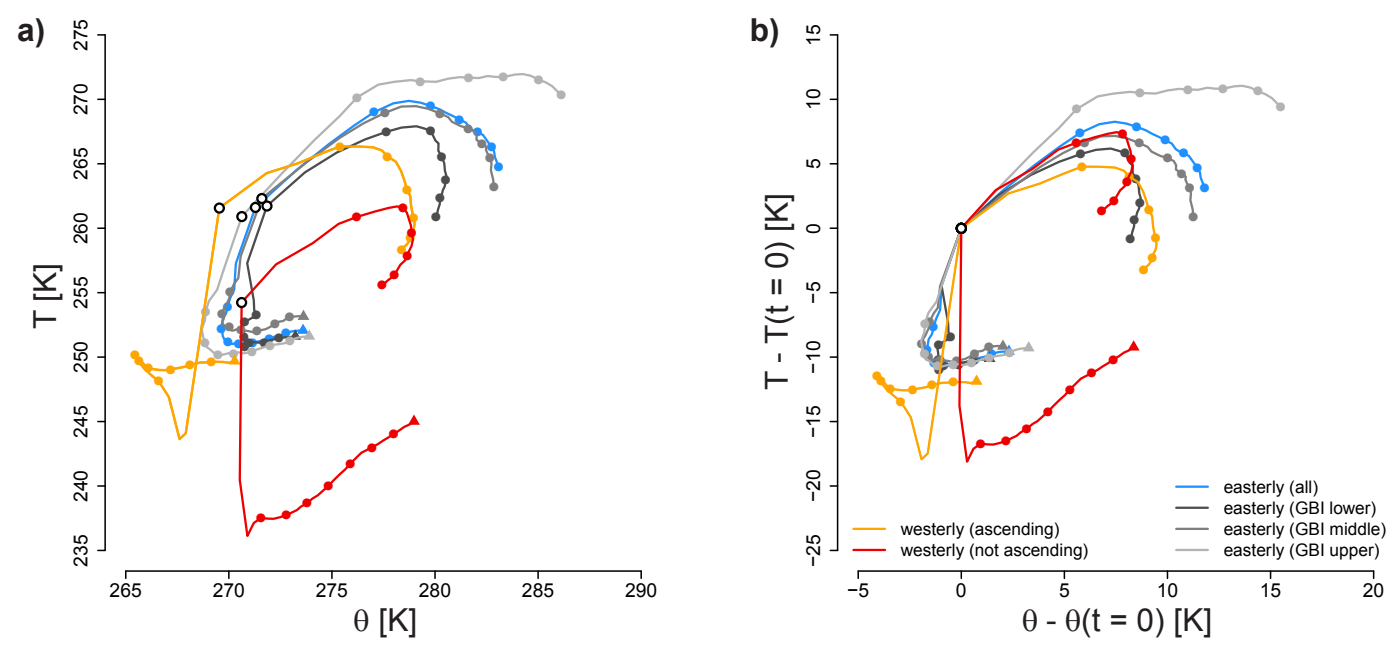

Figure 5: $\theta-\mathrm{T}$ diagram for westerly ascending (orange) and non-ascending (dark red), as well as easterly (blue) median CAO trajectories. The sets of ascending (non-ascending) trajectories comprise the trajectories whose pressure at $t=-48 \mathrm{~h}$ is above (below) the median of westerly CAO trajectories. In addition, easterly CAO trajectories are split into lower (dark gray), middle (gray) and upper (light gray) terciles of the Greenland Blocking Index (cf. section 4.4.2). Values are (a) absolute and (b) relative to $t=0 \mathrm{~h}$ and they are shown for $-192 \mathrm{~h} \leq t \leq 144 \mathrm{~h}$ in 6-hourly intervals with dots every $24 \mathrm{~h}$. Times $t=-192 \mathrm{~h}$ and $t=0 \mathrm{~h}$ are highlighted by triangles and black circles, respectively. 

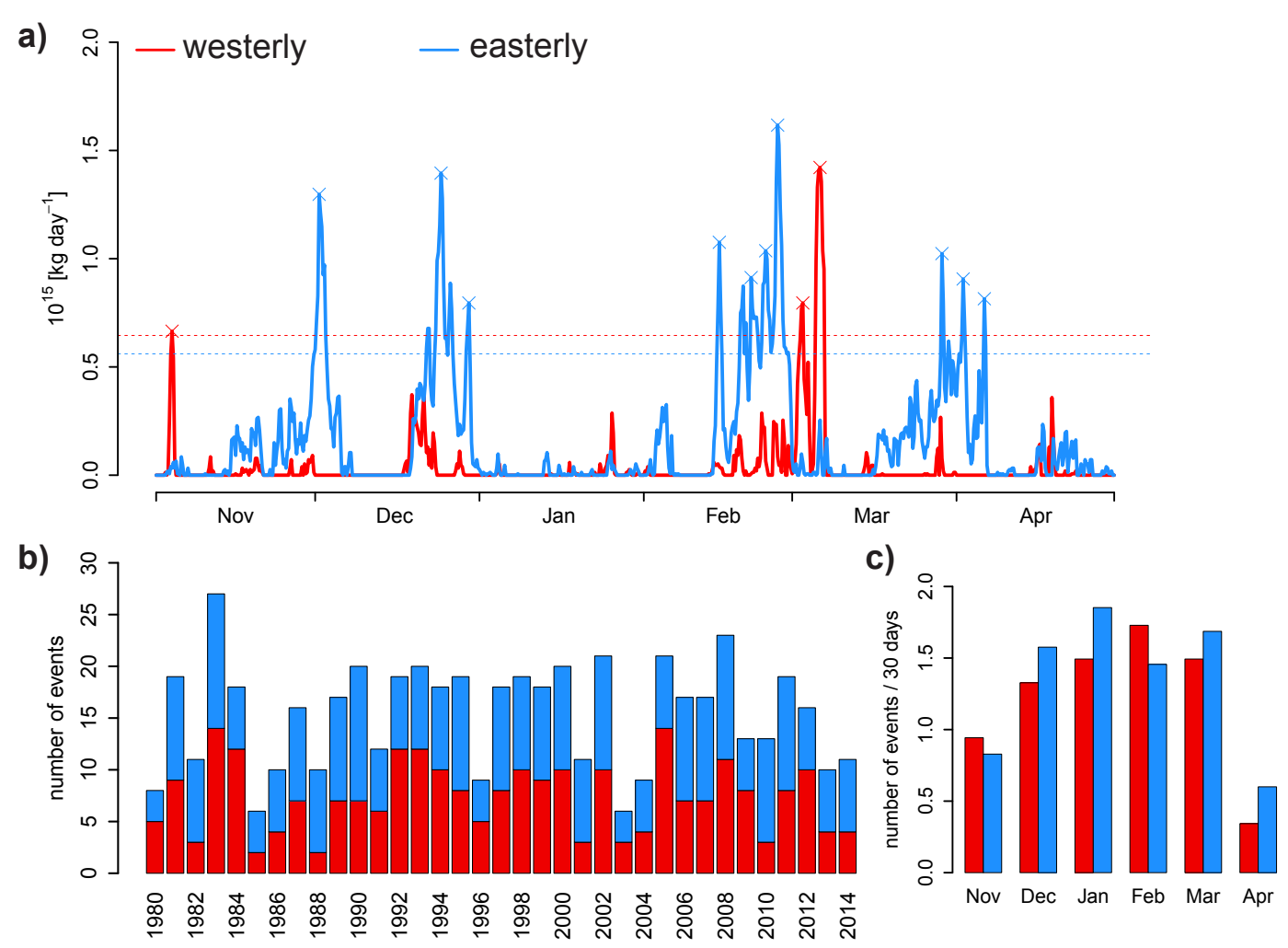

Figure 6: (a) Timeseries of formation rates of westerly (red) and easterly (blue) CAOs in units of $10^{15} \mathrm{~kg} \mathrm{day}^{-1}$ for extended winter $2009 / 2010$. Crosses show CAO events and dashed lines indicate the $95^{\text {th }}$-percentiles of the formation rates. (b) Inter-annual and (c) month-to-month variability of CAO events. The monthto-month variability is normalized in order to account for the different lengths of the months. 

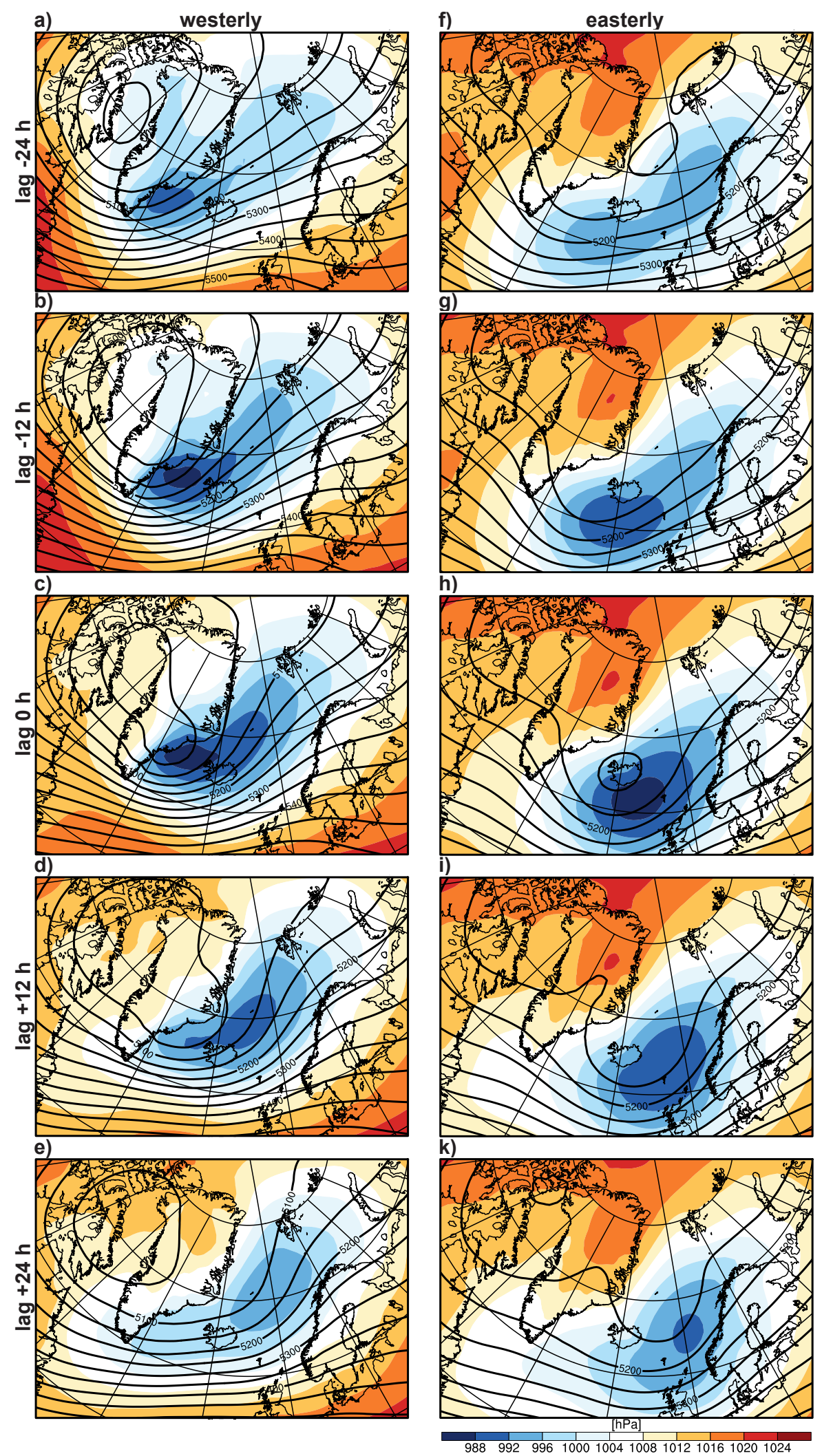

42

Figure 7: Lag composites for westerly $(\mathrm{a}-\mathrm{e})$ and easterly ( $\mathrm{f}-\mathrm{k}) \mathrm{CAO}$ events showing sea-level pressure (shading) and $500 \mathrm{hPa}$ geopotential height (black). Composites are shown at lags $(\mathrm{a}, \mathrm{f})-24 \mathrm{~h},(\mathrm{~b}, \mathrm{~g})-12 \mathrm{~h},(\mathrm{c}, \mathrm{h}) 0 \mathrm{~h},(\mathrm{~d}, \mathrm{i}) 12 \mathrm{~h}$ and $(\mathrm{e}, \mathrm{k}) 24 \mathrm{~h}$ relative to the peaks of the CAO events. 


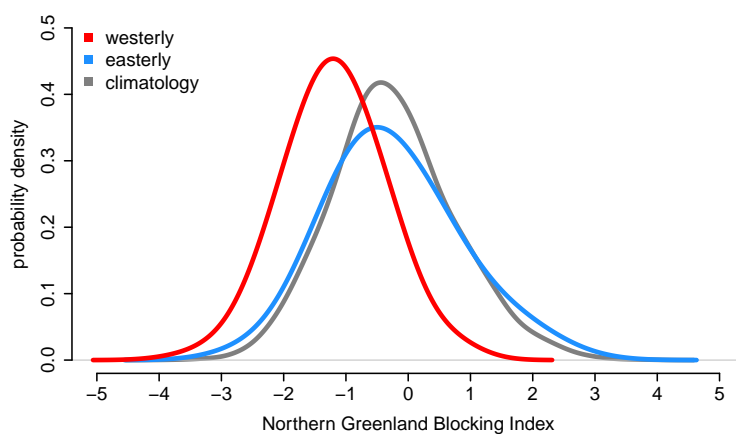

Figure 8: Probability density of the NGBI for extended winters (gray), westerly (red) and easterly (blue) CAO events. 
a) NGBI: lower tercile

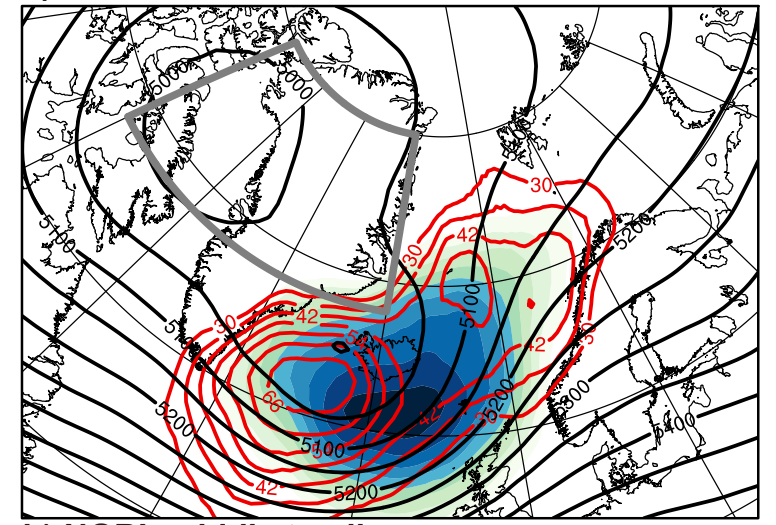

b) NGBI: middle tercile

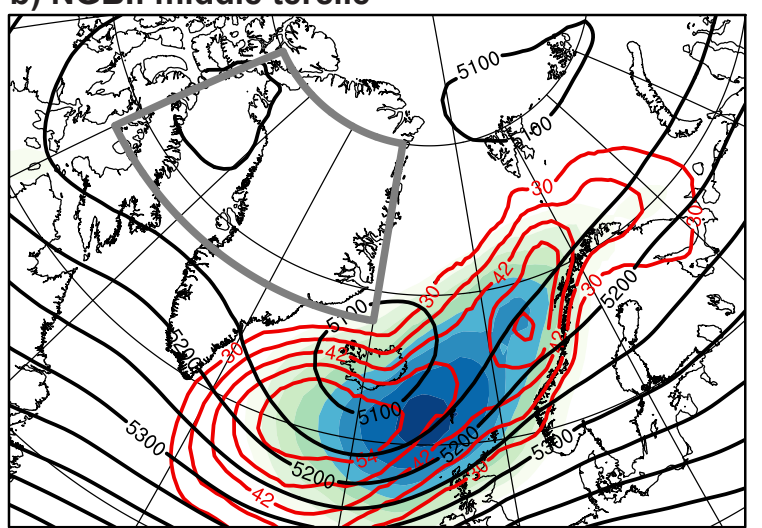

c) NGBI: upper tercile

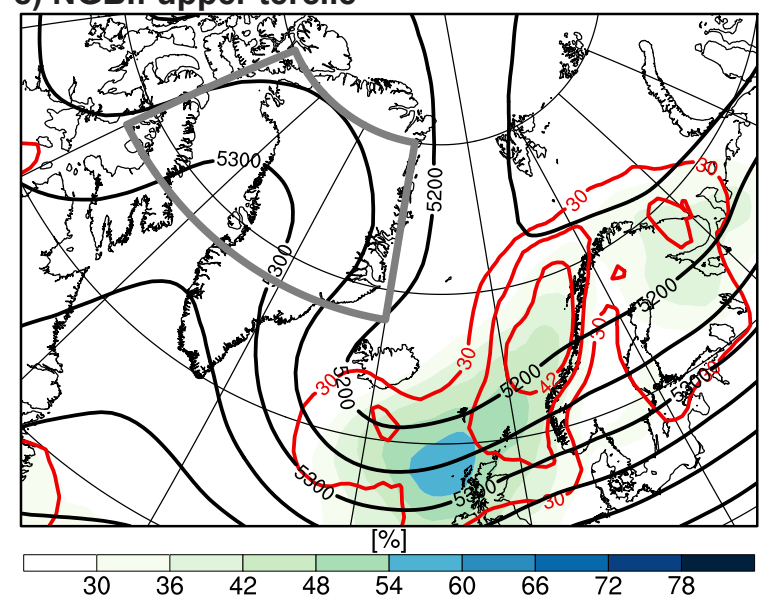

Figure 9: Cyclone frequency for easterly CAOs in $\%$ at lag $-24 \mathrm{~h}$ (red, from $30 \%$ in intervals of $6 \%$ ) and $0 \mathrm{~h}$ (shading) stratified into (a) lower, (b) middle, and (c) upper terciles of the NGBI. Composite $500 \mathrm{hPa}$ geopotential height at lag $0 \mathrm{~h}$ is shown by black contours. The region used for the NGBI calculation is outlined by the gray box. 

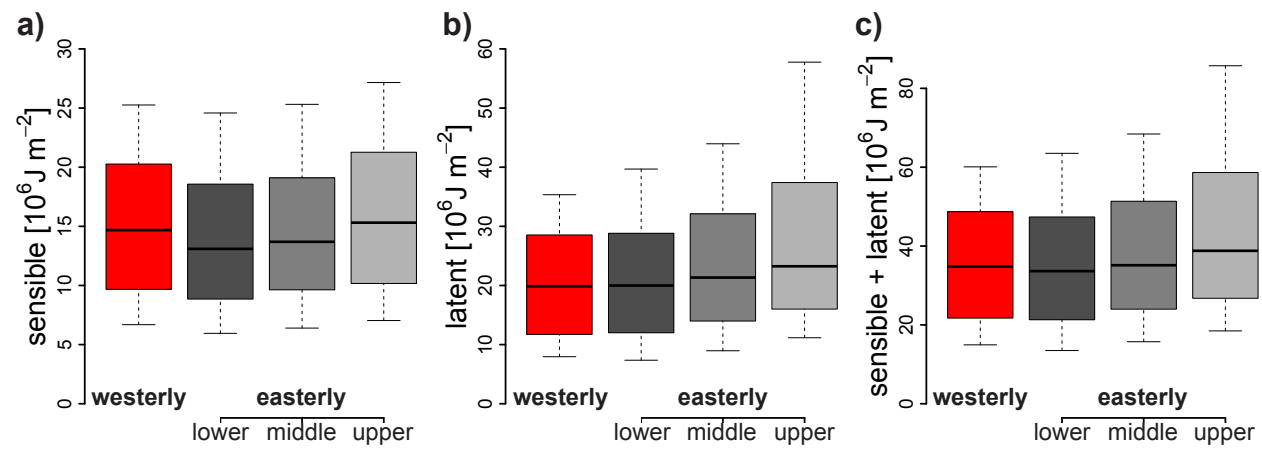

Figure 10: Boxplots of (a) sensible, (b) latent, and (c) sensible and latent heat fluxes accumulated over the CAO phase of westerly (red) and lower (dark gray), middle (gray), and upper (light gray) terciles of easterly CAO trajectories corresponding to CAO events. Whiskers indicate $10^{\text {th }}$ and $90^{\text {th }}$ - percentiles, respectively. 

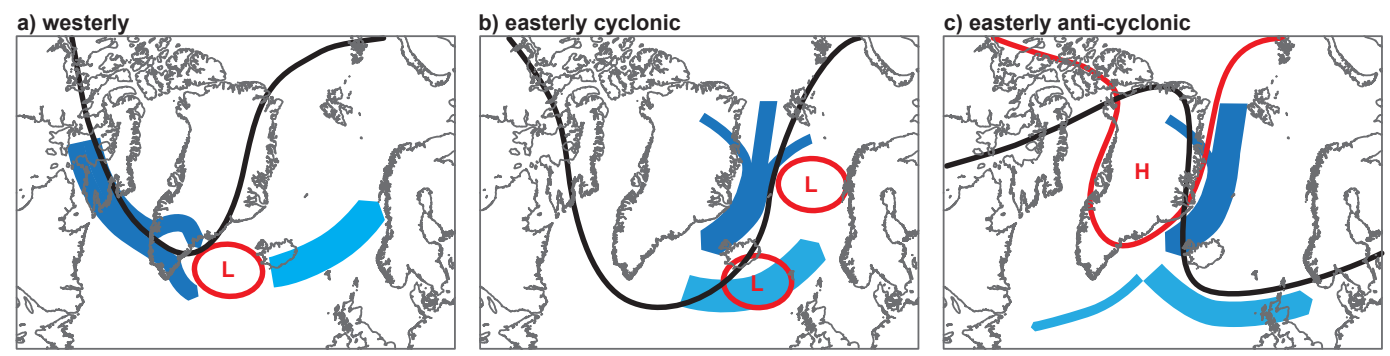

Figure 11: Schematic summarizing synoptic environments favorable for CAO formation in the Irminger Sea. The environments are (a) westerly, (b) easterly cyclonic, and (c) easterly anti-cyclonic. Shown are a typical contour line of $500 \mathrm{hPa}$ geopotential height (black), surface cyclones and anti-cyclones (red) all at the peak of CAO events. In addition, pathways of CAO airmasses prior to (dark blue) and after (light blue) CAO formation are depicted. 